\title{
FATORES HUMANOS NA AVALIAÇÃO E DESIGN DE INTERFACES DIGITAIS EDUCATIVAS PARA CRIANÇAS EM IDADE ESCOLAR
}

\author{
GUARALDO, Franceli \\ Centro Universitário Senac São Paulo \\ franceli.guaraldo@sp.senac.br \\ ANDRADE, André Carvalho \\ Centro Universitário Senac São Paulo \\ deco.candrade@gmail.com
}

\begin{abstract}
Resumo: Esse trabalho envolve uma abordagem multidisciplinar que busca integrar conceitos das áreas de Ergonomia e Usabilidade, Psicologia Cognitiva, Educação e Design. São apresentados como pontos relevantes para a discussão sobre o assunto os conceitos dos teóricos Jean Piaget e Lev Vigotsky sobre o desenvolvimento cognitivo humano, assim como, estudos que relacionam os critérios de usabilidade e de divertimento (fun) na avaliação de interfaces destinadas a crianças de diversas idades. Considerando a existência de poucos estudos sobre interfaces destinadas a crianças alfabetizadas nos primeiros anos de escolaridade, propõe-se um conjunto de critérios de avaliação e construção de interfaces digitais educativas para crianças de 8 a 10 anos de idade. A aplicabilidade desses critérios é investigada através da avaliação heurística de interfaces de dois softwares educativos utilizados no Brasil. Como uma segunda etapa a ser realizada posteriormente, é proposta a avaliação dos dois softwares a partir de observações e relatos de crianças da faixa etária considerada.
\end{abstract}

Palavras-chave: Interface Digital, Educação Infantil, Desenvolvimento Cognitivo, Usabilidade e Divertimento, Avaliação e Design

Abstract: This work involves a multidisciplinary approach in search of integration of concepts from Ergonomics and Usability, Cognitive Psychology, Education and Design areas. Presented as relevant points to the discussion on the subject are theoretical concepts of Jean Piaget and Lev Vygotsky on human cognitive development, as well studies in which criteria for usability and fun are related to the evaluation of interfaces for children of different ages. Since there are few studies about interfaces addressed to literate children in the first years of schooling, it is proposed a set of evaluation criteria and construction of educative digital interfaces applied to children 8-10 years old. The applicability of these criteria is 
investigated through a heuristic evaluation of two educational software used in Brazil. In a second stage to be held later, it is proposed the evaluation of two software from observations and reports of children in the age group considered.

Keywords: Digital Interface, Children Education, Cognitive Development, Usability and Fun, Evaluation and Design

\section{INTRODUÇÃO}

No Brasil, a discussão sobre o uso de computadores na educação vem ocorrendo desde a década de 1970. Com a contínua evolução dos sistemas digitais, este assunto é recorrente nos dias atuais, envolvendo reflexões sobre as necessárias mudanças dos paradigmas educacionais vigentes, assim como estudos sobre a qualidade e adequação das interfaces digitais educacionais às finalidades a que se destinam (PASSARELLI, 2007). Nesse contexto, diversos projetos e programas têm sido desenvolvidos visando a inserção do computador e de interfaces digitais nas práticas educativas, tais como One Laptop per Child, (MIT, Nicholas Negroponte e Seymond Papert) para países em desenvolvimento, o projeto E-Escolinha, iniciativa de avanço tecnológico em Portugal, em 2007, e, também o Prolnfo, Programa Nacional de Informática na Educação, desenvolvido pelo Governo Federal, para promover a inclusão digital nas escolas brasileiras.

Dessa forma, existe demanda crescente pelo design de interfaces digitais mais adequadas às práticas educacionais, havendo, portanto, necessidade de realizar pesquisas que apresentem e discutam as possibilidades de ação e experiência de seus usuários, as próprias crianças, com tais interfaces.

Através de uma abordagem multidisciplinar, nesse trabalho é elaborado um constructo teórico para a avaliação e design de interfaces educacionais para crianças em idade escolar, integrando pressupostos provenientes das áreas de ergonomia e usabilidade, psicologia cognitiva, educação e design.

Dessa forma, nessa pesquisa são abordados conceitos e critérios de avaliação que transitam no universo do design de interfaces e que se relacionam à ergonomia e usabilidade, assim como, apresenta propostas existentes de métodos e instrumentos de avaliação que visam a integração dos conceitos de usabilidade com aspectos decorrentes de conceitos da área de educação.

São considerados como pontos relevantes para a discussão sobre o assunto, os conceitos provenientes de duas importantes teorias de desenvolvimento cognitivo: a de Jean Piaget (2003) e Lev Vigotsky (1998), assim como levantamento de trabalhos que sistematizam conceitos e critérios de ergonomia e usabilidade para o universo infantil, e que fazem uso também de critérios relacionados à emotividade e ao divertimento (fun) para a avaliação e design de interfaces educacionais utilizadas por crianças de diversas idades (SHNEIDERMAN, 2004; MACFARLANE; SIM; HORTON, 2005; MACFARLANE; PASIALI, 2005; MANO, 2005). Considerando a existência de poucos estudos que abordem interfaces destinadas a crianças alfabetizadas nos primeiros anos de escolaridade, esse trabalho propõe um conjunto de critérios para a avaliação e design de interfaces digitais educativas destinadas a crianças de 8 a 10 anos de idade, 
e investiga a aplicabilidade desses critérios na avaliação de interfaces de dois softwares educativos utilizados no Brasil.

\section{DESENVOLVIMENTO}

\subsection{Ergonomia e Usabilidade}

Uma interface é, por definição, a área de comunicação entre o ser humano e um dispositivo virtual, ou seja, é a ferramenta com a qual interagimos com o universo da informação digital. As interfaces são elementos que contribuem para a experiência do usuário em utilizar os sistemas digitais, devendo torná-los agradáveis, intuitivos, eficientes e fáceis de operar.

As interações que uma interface proporciona podem variar de acordo com algumas características do usuário, do sistema ou da própria interface, tais como o grau de experiência do usuário em utilizar o sistema (operadores experientes interagem de forma diferente de operadores iniciantes), a frequência com que o sistema é utilizado (se esporádica ou corriqueiramente) e até mesmo o suporte físico do sistema (computadores rápidos ou lentos). Podemos dizer que uma interação satisfatória depende do acordo entre interface, usuário, tarefa (objetivo) e ambiente. A relação entre todos estes agentes é a essência da usabilidade.

Usabilidade, segundo a ISO 9241, é a capacidade que um sistema interativo oferece a seu usuário, em determinado contexto de operação, para a realização de tarefas de maneira eficaz, eficiente e agradável. Um problema de usabilidade pode ocorrer "quando uma característica do sistema interativo ocasiona perda de tempo, comprometendo a qualidade da tarefa ou mesmo inviabiliza sua realização" (CYBIS; BETIOL; FAUST, 2007). De acordo com os autores citados, os problemas de usabilidade devem ser identificados a partir de informações sobre o contexto de operação onde o problema pode ser observado, prováveis problemas de ergonomia em sua origem (algum aspecto inadequado na interface que provavelmente causa o problema de usabilidade) ou possíveis efeitos sobre o usuário e sua tarefa, incluindo a frequência com que esse problema se manifesta. Para que possamos identificar problemas e sugerir soluções quanto a usabilidade de um sistema, devemos inicialmente realizar uma avaliação a fim de identificar problemas relacionados a ergonomia da interface.

\subsection{Métodos de avaliação de interfaces digitais educativas para crianças}

São destacados aqui dois métodos de avaliação de interfaces que se propõem a utilizar aspectos pedagógicos e de usabilidade como critérios para avaliação de softwares educacionais.

A TICESE - Técnica de inspeção de conformidade ergonômica de software educacional (GAMEZ, 1998), como o próprio nome sugere, é uma metodologia de inspeção que se destina a apoiar o processo de avaliação de softwares educacionais, com vista a identificar suas qualidades e problemas ergonômicos. Propõem a integração entre os aspectos pedagógicos e de usabilidade no processo de avaliação.

Inicialmente foi pensada para auxiliar professores e avaliadores de softwares, envolvidos no processo de seleção de produtos com qualidade. Devido a grande ênfase dada aos aspectos relacionados à usabilidade, o autor sugere que a aplicação da técnica seja efetuada por uma equipe multidisciplinar, com a presença de profissionais com conhecimentos em ergonomia e interfaces homem-computador. 
O processo de avaliação pela TICESE envolve três módulos: o módulo de classificação cuja intenção é classificar o software a partir dos seus atributos e proposta pedagógica; o módulo de avaliação, que avalia a conformidade com os padrões ergonômicos de qualidade do software educacional. Incide tanto sobre os recursos pedagógicos e de apoio à aprendizagem utilizada, como sobre os aspectos ergonômicos de interface do produto, com uma adaptação dos critérios ergonômicos de Bastien e Scapin; e, o módulo de avaliação contextual que se refere à verificação da adequabilidade do software em um dado contexto pedagógico ou situação específica.

A MAQSEI - Metodologia de Avaliação de Qualidade de Software Educacional Infantil é uma proposta metodológica que abrange aspectos técnicos e pedagógicos (ATAYDE; TEIXEIRA; PÁDUA, 2003). Por aspectos técnicos os autores consideram a avaliação da usabilidade, ou seja, a qualidade da interação usuário-computador proporcionada pela interface do software. Já por aspectos pedagógicos consideram a avaliação da conveniência e da viabilidade de utilização do software em situações educacionais.

É destinada a atender às necessidades de instituições de ensino, que carecem de processos efetivos e confiáveis para a seleção de software educativo e serem adotados para apoio ao ensino.

Para sua aplicação, foi desenvolvida uma série de heurísticas pedagógicas e de usabilidade para nortear a análise de um software educacional. De um modo geral, algumas heurísticas foram especialmente desenvolvidas para esta finalidade e outras foram adaptadas de critérios ergonômicos conhecidos, como os de Bastien e Scapin, sempre com base em requisitos adequados ao público infantil. Os autores sugerem que as heurísticas desenvolvidas no estudo podem servir como referencial técnico e pedagógico para avaliadores e desenvolvedores.

A metodologia é caracterizada pela união de algumas técnicas de avaliação de usabilidade tradicionais, como a aplicação de listas de verificação, entrevistas, questionários e testes com usuários.

Os dois métodos analisados abordam aspectos referentes à usabilidade e aprendizado. Embora o cuidado com a questão pedagógica seja apreciável, ambos deixam de lado aspectos fundamentais como o desenvolvimento cognitivo da criança e suas implicações sobre o aprendizado.

A TICESE, percebe-se pelas referências bibliográficas que a fundamentam, esboça uma intenção de utilização desta questão, mas tal preocupação não se reflete na proposta de metodologia de análise. Esta, inclusive, toca apenas tangencialmente nas questões referentes ao aprendizado, tendo uma abordagem muito forte nos conceitos de usabilidade.

A MAQSEI consegue trabalhar de forma mais efetiva a relação entre usabilidade e aprendizado, em uma tentativa de diminuir o caráter tecnicista da avaliação de usabilidade, utilizando uma abordagem equilibrada também com questões pedagógicas. A metodologia trata muito brevemente da questão relacionada aos diferentes comportamentos de crianças em diferentes idades. Através de um critério denominado "Adaptabilidade", proposto pelos autores, diz respeito à capacidade do software em se adaptar às necessidades e preferências de diferentes perfis de crianças, justificando tal ação pelo fato do software não conseguir abranger, a todo o momento, todo seu público alvo. 
Considera-se que, do mesmo modo que as interfaces devem acompanhar o estágio cognitivo em que se encontra a criança, os métodos de avaliação precisam ser adequados a estas características, pois só assim pode-se, de fato, avaliar a qualidade da interface enquanto facilitadora do aprendizado.

\subsection{Aprendizagem e desenvolvimento cognitivo da criança}

Para Jean Piaget (2003), o desenvolvimento cognitivo, importante para o aprendizado, provém das interações do sujeito com o objeto, numa relação de mútua interdependência e de co-especificação, o que pressupõe um comportamento ativo, de ações sobre esses objetos do mundo concreto. Nas experiências sensório-motoras as estruturas cognitivas se constroem e se desenvolvem, por meio dos elementos operatórios abstraídos das ações do sujeito sobre os objetos.

$\mathrm{Na}$ teoria de Piaget destaca-se ainda a forma com que ele classifica - por faixa etária - e descreve as etapas do desenvolvimento humano. A faixa etária abordada nesse trabalho (de 08 a 10 anos) corresponde ao estágio operatório concreto, no qual ocorre: o desaparecimento da linguagem egocêntrica, o início de construção lógica do pensamento com a coordenação de diferentes pontos de vista, a interiorização do pensamento ou operações mentais realizadas a partir de elementos concretos, que se referem à própria realidade, ações interiorizadas reversíveis, o desenvolvimento do raciocínio, e a noção de conservação, que permite a emissão de julgamentos baseados em sistemas organizados de crenças e/ou sistemas conceituais já estabelecidos.

Para Lev Vigotsky (1998), aprendizado e desenvolvimento estão interrelacionados; o desenvolvimento é um processo cujo ponto determinante é a união do pensamento com a linguagem (universo simbólico). Destaca-se a tese de que a aprendizagem estimula o desenvolvimento e a importância da mediação simbólica neste contexto, na medida em que a criança fica mais velha.

As teorias que estudam o desenvolvimento cognitivo humano indicam que crianças em diferentes faixas etárias possuem características cognitivas distintas (PIAGET, 2003). Então é razoável considerar que conceitos e critérios que podem ser aplicados para crianças menores dificilmente serão adequados para crianças um pouco maiores. Estas diferenças de desenvolvimento cognitivo são decisivas no processo educacional por que passam as crianças. Portanto, as interfaces digitais, inseridas neste contexto, devem acompanhar essas diferenças, pois só assim conseguem atingir todo seu potencial como facilitador para aquisição de conhecimento por parte das crianças.

\subsection{Usabilidade e divertimento ( fun) em interfaces para crianças}

Em se tratando de interfaces educacionais, se faz necessário um cuidado especial com a usabilidade pois esta é essencial para determinar se um determinado software ou interface educativa pode facilitar a aquisição de conhecimento. Se a criança acha que o sistema é muito difícil de usar, isto pode influenciar em sua capacidade de absorver o conteúdo pedagógico nele inserido.

Em interfaces para crianças, além das metas tradicionais de usabilidade (eficácia, eficiência e satisfação), necessitam serem incorporadas metas que particularmente às crianças possam ser cruciais para facilitar sua interação com o sistema. 
Estudos indicam que na avaliação de interfaces para crianças, além dos critérios já bem conhecidos de usabilidade, é necessário incorporar critérios tais como desafio, curiosidade, fantasia e controle (MAC FARLANE; PASIALI, 2005). Um aspecto relevante para avaliar se o sistema é ou não adequado para educação infantil está relacionado ao conceito de fun ou enjoyment (entretenimento, divertimento, diversão).

Shneiderman (2004) sugere que interfaces divertidas tem o poder de engajar totalmente as pessoas na experiência do momento, numa "experiência de fluxo" (CSKSZENTMIHALYI, 1999), propiciando uma concentração intensa, um alto e criativo desempenho para realizar as metas propostas, e sugere que aspectos relacionados à diversão deveriam estar integrados aos aspectos de funcionalidade, confiabilidade e usabilidade, construindo assim uma concepção de usabilidade mais abrangente (funin-doing). Os aspectos de usabilidade e fun estão inter-relacionados, e devem ser mais investigados no contexto do aprendizado através de interfaces educacionais (MACFARLANE; SIM; HORTON, 2005).

Cabe ressaltar que fun não deve ser confundido com satisfação. Em usabilidade, a satisfação implica no conforto do usuário em utilizar o sistema para atingir metas. Fun implica em interfaces divertidas, numa experiência alegre, desafiante, prazeirosa que a interação pode proporcionar; no quanto a interface consegue atrair, capturar e prender a atenção.

\subsection{Proposta de Critérios de Avaliação e Construção de Interfaces Para Crianças na Faixa de 8 a 10 Anos}

Com base nas teorias de desenvolvimento cognitivo estudadas, e na análise de trabalhos sistematizam conceitos e critérios de ergonomia, usabilidade e divertimento (fun) para a avaliação e design de interfaces educacionais utilizadas por crianças de diversas idades, são propostos um conjunto de critérios de avaliação e construção de interfaces digitais educativas para crianças de 8 a 10 anos de idade.

\subsubsection{Aparência ou estética atrativa}

Diversos estudos indicam que as crianças julgam muito rapidamente a aparência estética de uma interface, sendo que uma má impressão pode desestimular a criança a interagir com o sistema, prejudicando seu envolvimento com as dinâmicas propostas pela interface. Assim, a interface deve privilegiar recursos (cores, formas, imagens, sons, etc.) que envolvam a criança e criem uma atmosfera de expectativa para descobrir as atividades que podem ser desenvolvidas na plataforma.

\subsubsection{Utilização de signos adequados}

O uso de signos adequados ao estágio cognitivo atual da criança é fundamental para facilitar a aprendizagem e o desenvolvimento de operações superiores. Isso se relaciona a: se os signos representam objetos pertencentes ao universo da criança, se os objetos se relacionam a situações concretas, se existe consistência de utilização dos elementos visuais (cores, layout, tipografia, etc) além a terminologia utilizada em menus e a estrutura de navegação entre as seções.

\subsubsection{Estímulo à navegação exploratória}

Uma navegação rígida pode mecanizar os processos de interação e num curto prazo desestimular o uso continuado da interface. É importante ainda considerar se 
existe excesso de elementos que tirem a atenção da realização da atividade proposta, e se os recursos de localização e controle da navegação são disponibilizados.

\subsubsection{Estímulo ao pensamento lógico}

Aqui, pode-se avaliar se a atividade proposta através da interface estimula a criança a pensar a realizar a operação em detrimento de tentativa e erro.

\subsubsection{Estímulo à imaginação}

Nesse critério é considerado se a interface estimula e/ou facilita a solução de problemas mentalmente, e se a criança, em algum momento de sua interação, é convidada a utilizar a sua imaginação para realizar alguma atividade.

\subsubsection{Estímulo ao divertimento}

Diversão pode ser considerada uma das características fundamentais em um sistema educativo para crianças. Uma atividade envolvente e divertida motiva a criança e a convida a interagir continuadamente com a interface. $\mathrm{O}$ uso prazeroso e estimulante do sistema favorece a assimilação dos conteúdos pedagógicos presentes nas atividades de aprendizado. Atrair e, principalmente, manter a atenção das crianças nos desafios que a atividade promove é de grande importância para que os objetivos das interfaces educacionais sejam alcançados.

\subsubsection{Mensagens compreensíveis e estimulantes}

O tom das mensagens emitidas (alertas, instruções, etc.) deve ser de fácil assimilação e sempre em uma linguagem que seja compreensível pelas crianças, respeitando suas características e estimulando sua interação com o sistema. Crianças tendem a ficar mais motivadas e concentradas na realização de atividades se o sistema Ihes fornecer mensagens constantes (textuais, imagéticas, sonoras ou, de preferência, uma mesma mensagem em dois formatos distintos) de incentivo e orientação durante a interação, assim como mensagens ou feedbacks em resposta à suas ações no sistema (sinais sonoros ao clique do mouse ou cursor que se modifica em áreas "clicáveis", por exemplo). Além disso, pode-se considerar se mensagens de erro são adequadas e informativas, se as instruções são apresentadas de forma clara e legível, e se existem recursos que podem propiciar alguma ajuda disponível aos usuários.

\subsection{Avaliação de interfaces digitais educativas a partir dos critérios propostos}

Para investigar a aplicabilidade dos critérios propostos, foi realizada uma avaliação heurística de interfaces de dois softwares educacionais destinados a crianças da faixa etária considerada. O primeiro deles foi o sistema operacional Linux Educacional 3.0, que tem sido distribuído nas escolas públicas brasileiras através do programa Prolnfo. O segundo é o software multimídia Os Caça Pistas, desenvolvido pela empresa Divertire, aplicativo educativo, disponível no mercado, destinado a crianças entre sete e dez anos de idade.

Como ambos os softwares são compostos por uma série de atividades, após uma breve apresentação da interface principal dos softwares, foi selecionada uma atividade específica para a realização da avaliação em cada software. Foram selecionadas atividades que os dois programas relacionadas à disciplina de Geografia e com a mesma temática na expectativa de manter uma uniformidade entre as análises. 
O aplicativo KGeography permite ao aprendiz selecionar em uma lista mapas de todos os continentes e de diversos países do mundo. Em cada um dos mapas, pode se "navegar" descobrindo, através dos cliques, os nomes, capitais e bandeiras dos países e estados. Há também a opção de atividades do tipo perguntas e respostas. $O$ usuário escolhe o tipo e a quantidade de questões que deseja responder e o sistema gera as perguntas e emite um parecer final sobre a quantidade de erros e acertos. As perguntas são geradas aleatoriamente, relacionadas ao mapa em questão.

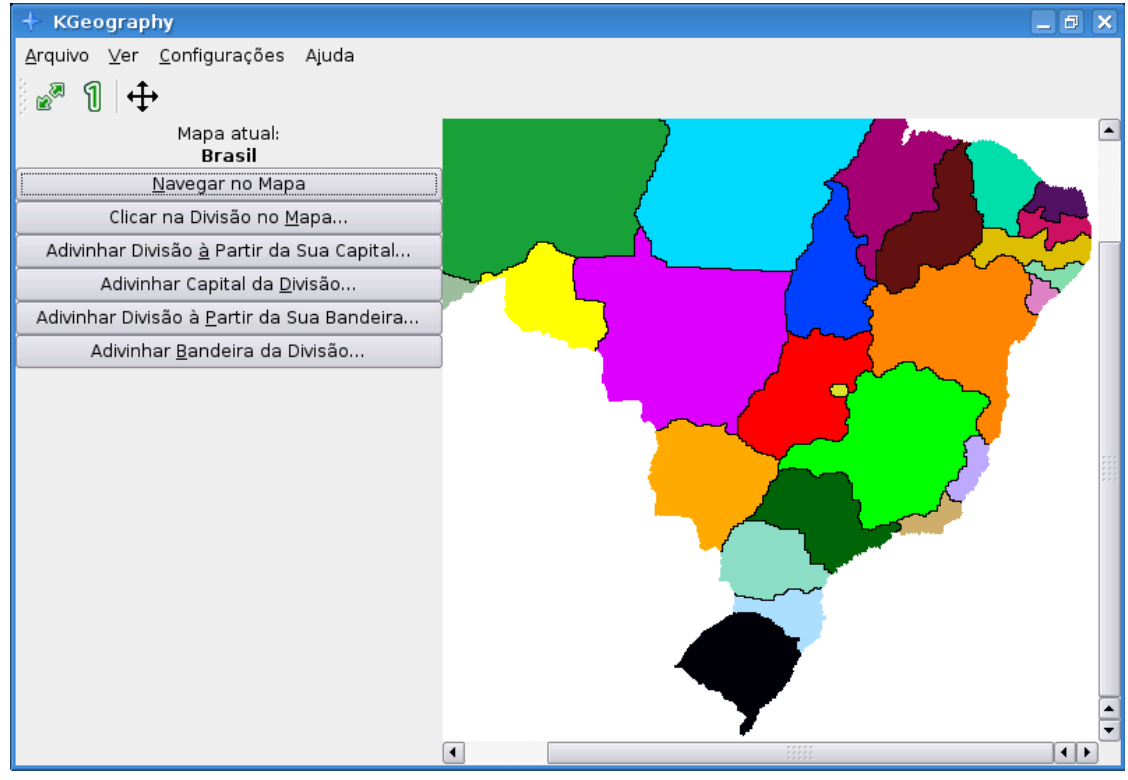

Figura 1 - Interface do aplicativo KGeography do sistema Linux Educacional 3.0. Fonte: Tela capturada do próprio sistema Linux Educacional 3.0.

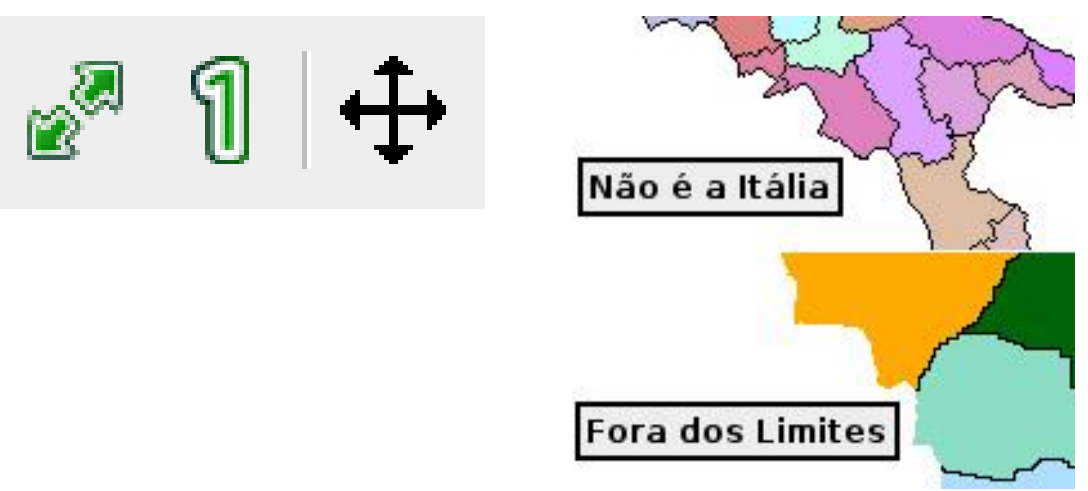

Figura 2 -Aplicativo KGeography; signos dos menus (à direita) e mensagens de erro (à esquerda). Fonte: Telas capturada do próprio sistema Linux Educacional 3.0.

No módulo de Geografia do software "Os Caça Pistas", o usuário é convidado a responder questionamentos a partir de sua observação dos mapas apresentados. Há opção de se definir previamente o nível de dificuldade das questões, e a forma com que alguns elementos são apresentados variam também em função disso. $\mathrm{O}$ sistema gera uma informação (chamada de Roteiro de Viagem), o usuário faz a associação entre o local informado e um signo no mapa. Para responder, "leva" (clica, segura e arrasta) o marcador até o país que julgar correto. 
A avaliação dos aplicativos foi realizada a partir dos critérios citados acima pelos próprios autores desse trabalho, para a qual foi confeccionou-se um formulário padronizado e específico para essa finalidade. No decorrer da avaliação de cada critério, os problemas encontrados foram classificados a partir de uma escala com os graus de severidade propostos por Jakob Nielsen (de 1 a 4 , onde 1 equivale a problema cosmético, 2 a problema pequeno, 3 a problema grande, e 4 a problema catastrófico).

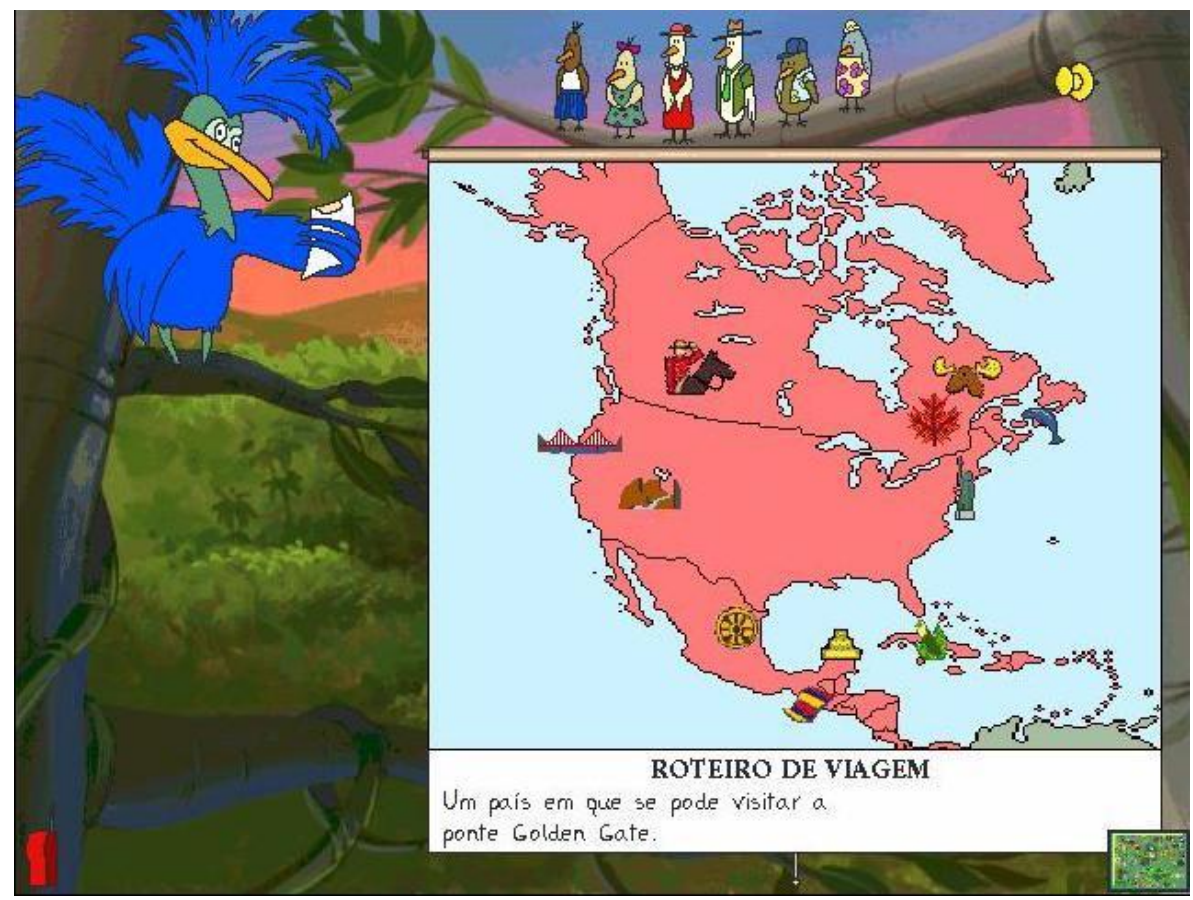

Figura 3 - Interface da atividade de Geografia do software Os Caça Pistas.

Fonte: Tela capturada do próprio software Os Caça Pistas

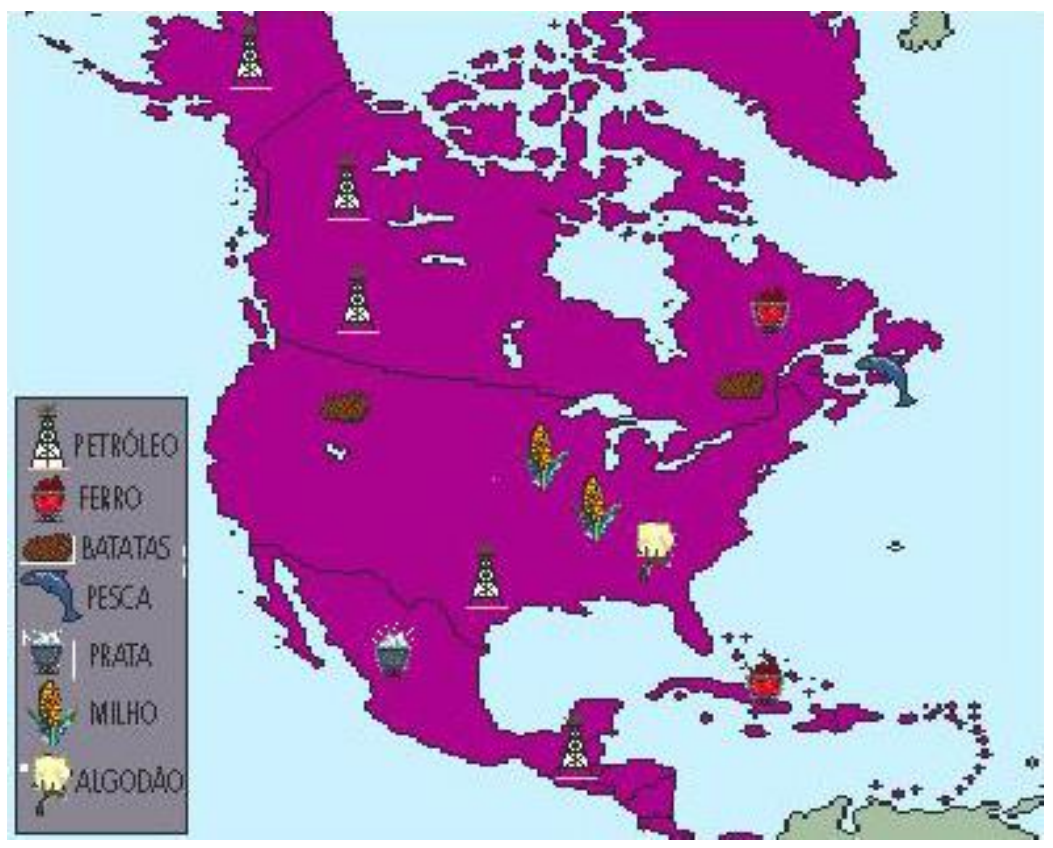

Figura 4 - Legendas do mapa da atividade de Geografia do software Os Caça Pistas. Fonte: Tela capturada do próprio software Os Caça Pistas 
De modo geral, os resultados obtidos na avaliação indicam que embora a interface do aplicativo "KGeography" possua condições que asseguram a legibilidade, a apresentação visual da interface é "neutra", e não tem qualquer relação com o universo infantil. $O$ uso de cores se reserva aos mapas, e mesmo assim sua utilização caótica não gera nenhum tipo de sensação agradável. Os elementos são frios e não despertam a curiosidade ou motivam a criança a interagir com a interface.

Com relação ao menu principal da interface, os signos utilizados não dizem respeito ao universo infantil. Mesmo para adultos há uma associação dúbia, como por exemplo, um número "1" representando a função "tamanho original". Não são utilizados signos visuais (apenas texto) no menu das atividades. Nas atividades as imagens se limitam aos mapas e bandeiras. A navegação é mecanizada e não há estímulos visuais outros que a estimulem a não ser a necessidade de encontrar as respostas.

A interface pouco estimula o pensamento. O usuário apenas tem de decorar informações que serão cobradas nas perguntas padronizadas. Não há a necessidade de reflexão sobre a pergunta, apenas de lembrar qual a resposta. A interface privilegia apenas a memória em detrimento a imaginação. As questões não requerem nenhum tipo de raciocínio ou representação. A falta de signos ou imagens não contribui para um envolvimento afetivo e não estimulam a criança a pensar situações fora do ambiente delimitado pela interface.

Além do mais, o sistema não propicia nenhum tipo de divertimento aparente aos usuários. As perguntas são repetitivas, e não há um nível de dificuldade ou desafio crescente que possa estimular o uso aprofundado da interface. Não há meios de manter a atenção ou a motivação da criança em utilizar reiteradas vezes o aplicativo.

A apresentação visual da interface das atividades de geografia do software "Os Caça Pistas" utiliza recursos utilizados (cores, sons, animações) criando um ambiente agradável e provavelmente estimula as crianças à interagir com o sistema, embora existam problemas de legibilidade; os signos são muito pequenos e poucos definidos.

A navegação é até certo ponto linear e não exploratória. O usuário deve realizar aquilo que lhe é pedido. Os signos presentes na atividade não são suscetíveis de exploração, apenas de observação. São fornecidos poucos subsídios para que a criança construa um raciocínio lógico e a partir daí consiga responder a questão. A interface peca em não permitir nenhum tipo de pesquisa, seja em sua base de dados ou em bases externas. A criança que não reconhece o signo em questão acaba tendo que utilizar a metodologia de tentativa e erro, pois a interface em nada contribui para que ela consiga resolver a questão de um modo lógico.

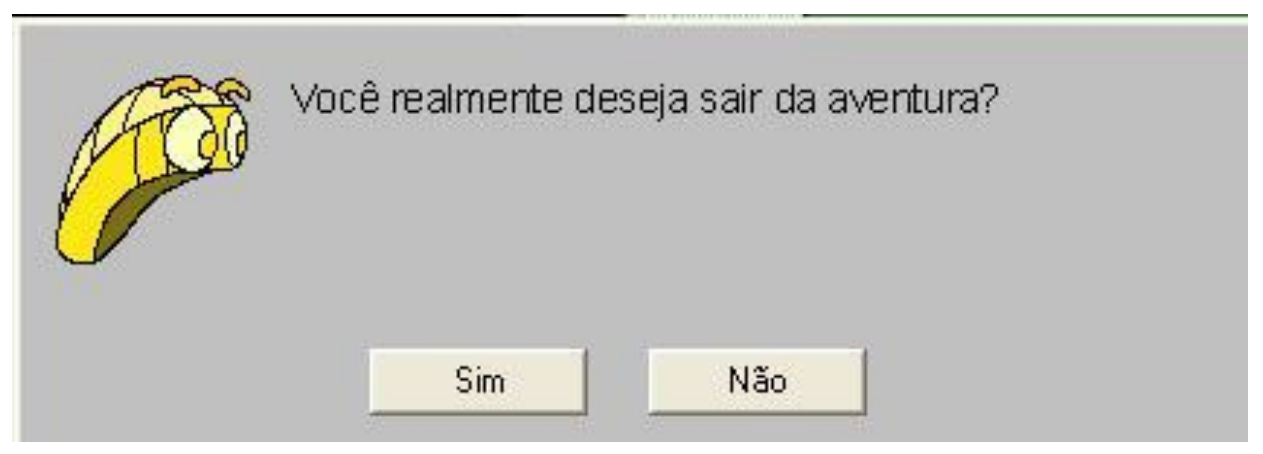

Figura 5 - Mensagem de alerta para ações cruciais das atividades de Geografia do software Os Caça Pistas. Fonte: Tela capturada do próprio software Os Caça Pistas 
A atividade possui um componente lúdico interessante que tende a se tornar um fator motivacional importante para que a criança expresse sua imaginação. Existe uma espécie de narrativa na qual a atividade está embarcada (os pássaros pequenos querem viajar, e só conseguem quando o usuário acerta o local previsto em seu roteiro de viagem) e através disso cria-se um cenário propício para que a criança interaja com a interface de um modo mais afetivo e calcado pela imaginação.

As mensagens que o sistema emite às crianças são adequadas. As explicações quanto à dinâmica da atividade são claras e passíveis de compreensão por parte das crianças. Em caso solução do problema, além do estímulo visual interativo (o pássaro voando para as férias) é emitida uma mensagem de congratulações, motivando a criança a tentar solucionar a próxima questão. Todas as mensagens são emitidas e ficam disponíveis (caso das instruções) através de áudio.

No caso de erro quanto à realização da tarefa, a mensagem é estimulante (do tipo "eu sei que você consegue") e não repreensiva. Nestes casos é emitida uma mensagem sonora para que o usuário tente outra alternativa e o tolken (a tachinha) volta automaticamente ao seu local de origem. Fora isso, o sistema não oferece muitas possibilidades de erros graves na navegação. São emitidas mensagens de alerta e confirmação de ações cruciais, como fechar a atividade.

\section{CONCLUSÃO}

A avaliação das interfaces sob a luz dos critérios ergonômicos formulados a partir do constructo teórico dessa pesquisa possibilitou a observação de diversos aspectos positivos e negativos das interfaces existentes nos aplicativos dos softwares estudados. Foi possível observar, por exemplo, que embora uma das interfaces (Os Caça Pistas) não apresente muitos problemas graves de usabilidade, nem sempre a estrutura da atividade oferece a possibilidade de desenvolvimento de pensamento lógico por parte da criança, função esta que, segundo as teorias cognitivistas, é primordial para que a criança se desenvolva e atinja estágios os superiores de maturação cognitiva.

Observa-se também que a utilização de uma dinâmica lúdica de entretenimento envolve a criança na atividade que a interface propõe, mantendo sua motivação e estimulando aspectos como imaginação e divertimento.

Foi possível constatar que uma abordagem de avaliação e/ou design de interfaces que utilize questões referentes ao desenvolvimento cognitivo da criança oferece uma visão mais abrangente das qualidades esperadas e encontradas na interface, principalmente com relação à função central do software educativo, que é facilitar o aprendizado através do computador. Sem estas questões, possivelmente seriam encontrados resultados puramente técnicos, que possivelmente não são tão adequados para avaliações desses tipos de interfaces.

Possivelmente, um primeiro desdobramento que esta pesquisa possa ter seja a validação dos critérios propostos, através da avaliação de um número maior de interfaces de outras atividades propostas pelos aplicativos em questão. Em um segundo momento, é importante a realização de uma pesquisa de campo, com observações e relatos de usuários da faixa etária considerada, para a validação e/ou refinamento dos critérios desenvolvidos nesse trabalho. 


\section{REFERÊNCIAS}

ATAYDE, Ana Paula Ribeiro; TEIXEIRA, Adla Betsaida Martins; PÁDUA, Clarindo Isaías Pereira da Silva. SIMPÓSIO BRASILEIRO DE INFORMÁTICA NA EDUCAÇÃO, Rio de Janeiro. MAQSEI - Uma Metodologia de Avaliação de Qualidade de Software Educacional. Rio de Janeiro, IM/UFRJ, 2003.

BLYTHE. Mark A. et. Al. Funology: From Usability to Enjoyment. Dordrecht: Kluwer Academic Publishers, 2004.

CSIKSENTMIHALYI, Mihaly. A descoberta do fluxo: a psicologia do envolvimento com a vida cotidiana. Rio de Janeiro: Rocco, 1999.

CYBIS, Walter; BETIOL, Adriana Holtz; FAUST, Richard. Ergonomia e usabilidade: conhecimentos, métodos e aplicações. São Paulo: Novatec, 2007.

GAMEZ, Luciano. TICESE - Técnica de Inspeção de Conformidade Ergonômica de Software Educacional. 1998. Dissertação (Mestrado em Engenharia Humana) - Escola de Engenharia da Universidade do Minho.

MANO, Alexandre Sérgio. Interfaces de computadores para crianças - avaliação e construção. 2005. 120f. Tese (Mestrado em Informática) - Escola de Engenharia da Universidade do Minho.

MACFARLANE, Stuart; PASIALI, Anastacia. Adapting the Heuristic Evaluation Method for Use With Children. Workshop on Child Computer Interaction Methodological Research. Interact, 103-109, 2005. Disponível na internet por http em: $<$ http://www.chici.org/references/adapting the heuristic evaluation.pdf $>$. Acesso em 15 Out. 2010.

MACFARLANE, Stuart; SIM, Gavin; HORTON, Matthew. Assessing Usability and Fun in Educational Software. Proceedings of the $\mathbf{2 0 0 5}$ Conference on Interaction Design and Children. ACM New York, NY, USA, 2005. Disponível na internet por http em: http://dl.acm.org/ citation.cfm? id=1109554. Acesso em 11 nov. 2010.

PASSARELLI, Brasilina. Interfaces digitais na educação: @lucin[ações] consentidas. São Paulo: Escola do Futuro da USP, 2007.

PIAGET, Jean. Seis estudos de psicologia. Rio de Janeiro: Forense Universitária, 2003.

SHNEIDERMAN, Ben. Designing for Fun: How Can We Design User Interfaces to Be More Fun? ACM Interactions 11, 5, 48-50, 2004. Disponível na internet por http em: <http//www.cs.umd.edu/ ben/Fun-p48-shneiderman.pdf>. Acesso em 02 Nov. 2010.

VIGOTSKY, Lev. A formação social da mente. São Paulo: Martins Fontes, 1998. 